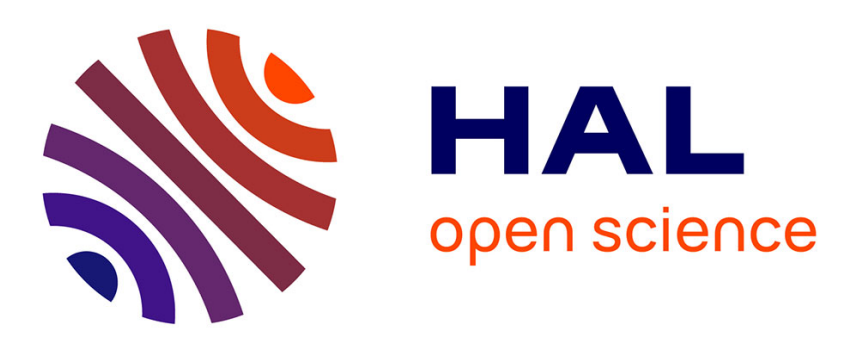

\title{
Phase transformations in microcrystalline cellulose due to partial dissolution
}

\author{
Benoît J.C. Duchemin, Roger H Newman, Mark P Staiger
}

\section{To cite this version:}

Benoit J.C. Duchemin, Roger H Newman, Mark P Staiger. Phase transformations in microcrystalline cellulose due to partial dissolution. Cellulose, 2007, 14 (4), pp.311-320. 10.1007/s10570-007-9121-4 . hal-02922530

HAL Id: hal-02922530

https://hal-normandie-univ.archives-ouvertes.fr/hal-02922530

Submitted on 3 Sep 2020

HAL is a multi-disciplinary open access archive for the deposit and dissemination of scientific research documents, whether they are published or not. The documents may come from teaching and research institutions in France or abroad, or from public or private research centers.
L'archive ouverte pluridisciplinaire HAL, est destinée au dépôt et à la diffusion de documents scientifiques de niveau recherche, publiés ou non, émanant des établissements d'enseignement et de recherche français ou étrangers, des laboratoires publics ou privés. 


\title{
Phase transformations in microcrystalline cellulose due to partial dissolution
}

Benoît J.-C. Z. Duchemin ${ }^{\mathrm{a} *}$, Roger H. Newman ${ }^{\mathrm{b}}$ and Mark P. Staiger ${ }^{\mathrm{a}}$

a Department of Mechanical Engineering, University of Canterbury, Private Bag 4800, Christchurch, New Zealand

b Scion, Private Bag 3020, Rotorua, New Zealand

* Current authors for correspondence, e-mail: benoit.duchemin@univ-lehavre.fr or mark.staigerecanterbury.ac.nz (September 2020).

This is a Preprint version of: Duchemin, B.J.Z., Newman, R.H. \& Staiger, M.P. Phase transformations in microcrystalline cellulose due to partial dissolution. Cellulose 14, 311-320 (2007). DOI: 10.1007/s10570-007-9121-4

\begin{abstract}
All-cellulose composites were prepared by partly dissolving microcrystalline cellulose (MCC) in an 8.0 wt.\% LiCl/DMAc solution, then regenerating the dissolved portion. Wide-angle X-ray scattering (WAXS) and solid-state ${ }^{13} \mathrm{C}$ NMR spectra were used to characterize molecular packing. The MCC was transformed to relatively slender crystallites of cellulose I in a matrix of paracrystalline and amorphous cellulose. Paracrystalline cellulose was distinguished from amorphous cellulose by a displaced and relatively narrow WAXS peak, by a 4 ppm displacement of the C-4 ${ }^{13} \mathrm{C}$ NMR peak, and by values of $\mathrm{T}_{2}(\mathrm{H})$ closer to those for crystalline cellulose than disordered polysaccharides. Cellulose II was not formed in any of the composites studied. The ratio of cellulose to solvent was varied, with greatest consequent transformation observed for $c<$ $15 \%$, where $c$ is the weight of cellulose expressed as $\%$ of the total weight of cellulose, $\mathrm{LiCl}$ and DMAc. The dissolution time was varied between 1 and $48 \mathrm{~h}$, with only small additional changes achieved by extension beyond $4 \mathrm{~h}$.
\end{abstract}


Keywords: All-cellulose composite; Cellulose I; Cellulose II; Cellulose IV; LiCl/DMAc; Microcrystalline cellulose; Solid-state ${ }^{13} \mathrm{C}$ NMR; X-ray diffraction.

Abbreviations: Microcrystalline cellulose (MCC), N,N-dimethylacetamide (DMAc), nuclear magnetic resonance (NMR), Wide-angle X-ray scattering (WAXS)

\section{Introduction}

Crystalline cellulose I has a tensile modulus of $138 \mathrm{GPa}$ (Nishino et al. 1995) and an ultimate tensile strength of at least $2 \mathrm{GPa}$ (Kroon-Batenburg et al. 1990; Yano et al. 2005), based on experimental data. If values as high as these could be achieved in reinforcement for composite materials, cellulose I could compete with steel or high-performance synthetic fibres (Nishino et al. 2004; Yano et al. 2005). Failure to achieve such high performance has been attributed to poor bonding between polar cellulosic fibres and less-polar polymer matrices (Bledzki and Gassan 1999; Lu and Wu 2000). Fibre-matrix compatibility can be improved by using cellulose itself as the matrix. Nishino et al. (2004) were the first to take this approach, introducing a new class of high strength, biodegradable materials known as all-cellulose composites.

While the mechanical properties of all-cellulose composites are known, there are very few references to the nature of the molecular packing in the matrix (Gindl and Keckes 2005). We sought insights from studies based on X-ray diffraction and solid-state ${ }^{13} \mathrm{C}$ NMR spectroscopy.

Two distinct strategies have been used in preparation of all-cellulose composites.

(1) Regeneration. Nishino et al. (2004) dissolved kraft fibre and regenerated the cellulose in the presence of ramie fibres. 
(2) Partial dissolution. Gindl and Keckes (2005) and Gindl et al. (2006a, b) partly dissolved cellulose I and precipitated the dissolved portion to form a matrix around the undissolved portion.

Similar composites have also been prepared by using esters such as cellulose acetate butyrate (CAB) as the matrix (Glasser et al. 1999; Gindl and Keckes 2004). While those composites were based primarily on cellulose, esterification altered the polarity of the matrix relative to the fibres and mechanical performance was not as good as for true all-cellulose composites. Gindl and Keckes (2004) reported a tensile strength of $129 \mathrm{MPa}$ for CAB reinforced with bacterial cellulose, compared with $480 \mathrm{MPa}$ for a true all-cellulose composite prepared by regeneration (Nishino et al. 2004).

We chose to follow Nishino et al. (2004), Gindl and Keckes (2005) and Gindl et al. (2006a, b) in preparing all-cellulose composites by partial dissolution in lithium chloride/N,Ndimethylacetamide ( $\mathrm{LiCl} / \mathrm{DMAc})$.

\section{Experimental}

\section{Preparation of composites}

Cellulose dissolution using DMAc initially involves an activation step in which the cellulose structure is first swollen via solvent exchange (Striegel 2002; Dupont 2003). The increased molecular mobility of cellulose allows the $\mathrm{LiCl} / \mathrm{DMAc}$ solvent to penetrate the cellulose structure more easily (McCormick et al. 1985; Ishii et al. 2003). In the present work, microcrystalline cellulose (MCC) powder (Avicel, Merck, particle size between 20 and $160 \mu \mathrm{m}$ ) was immersed in distilled water at $20^{\circ} \mathrm{C}$ for $48 \mathrm{hrs}$ and vacuum-filtered through Whatman No. 1 
filter paper, twice immersed in acetone (Biolab, laboratory grade) at $20^{\circ} \mathrm{C}$ for $24 \mathrm{hrs}$ and filtered through Whatman No. 1 filter paper to remove the acetone each time, twice immersed in DMAc (Merck, synthesis grade) at $20^{\circ} \mathrm{C}$ for $24 \mathrm{hrs}$ and each time filtered through Whatman No. 1 filter paper afterward, vacuum-dried for $48 \mathrm{hrs}$ at $60^{\circ} \mathrm{C}$ and then sieved $(90 \mu \mathrm{m})$. The activated $\mathrm{MCC}$ was vacuum-dried for a further $48 \mathrm{hrs}$ at $60^{\circ} \mathrm{C}$ and finally sealed in a container for storage.

\section{Partial dissolution}

A solution of $8.0 \%$ (by total weight) $\mathrm{LiCl}$ in DMAc was prepared by mixing $\mathrm{LiCl}$ (Unilab, $99 \%$ purity) and DMAc in a $2 \mathrm{~L}$ Schott bottle. The bottle was immediately sealed to prevent moisture absorption. The mixture was mechanically stirred for $24 \mathrm{~h}$ until the salt appeared to be completely dissolved.

A portion of $1 \mathrm{~g}$ activated MCC was immersed in a Petri dish containing sufficient $\mathrm{LiCl} / \mathrm{DMAc}$ to achieve cellulose concentrations of $c=5 \%, 10 \%, 15 \%$ or $20 \%$, where $c$ is expressed as $\%$ of the total weight of cellulose, $\mathrm{LiCl}$ and DMAc. The solution was placed under vacuum and stirred for $1 \mathrm{~h}, 4 \mathrm{~h}, 8 \mathrm{~h}$ or $48 \mathrm{~h}$ at $20^{\circ} \mathrm{C}$. The regeneration of the dissolved cellulose began initially with light spraying of water onto the surface of the gel in order to fix the shape of the final sample. The partially regenerated gel was then carefully transferred to a beaker and immersed in water for $48 \mathrm{hrs}$ at $20^{\circ} \mathrm{C}$. The water was changed at least every $24 \mathrm{~h}$. Residual $\mathrm{LiCl}$ or DMAc was removed by further thorough rinsing of the specimen with water. The specimens were then dried $48 \mathrm{~h}$ in a vacuum oven at $60^{\circ} \mathrm{C}$ to ensure complete solidification.

Wide Angle X-ray Scattering (WAXS) 
WAXS was performed on as-received MCC, activated MCC and on the final composites. X-ray patterns were obtained with a Philips PW1729 diffractometer using $\mathrm{Cu} \mathrm{K}_{\alpha}$ radiation $(\lambda=0.1540$ $\mathrm{nm}$ ), voltage of $50 \mathrm{kV}$ and current of $40 \mathrm{~mA}$ with $2 \theta$ increased in steps of $0.02^{\circ}$. The X-ray data was smoothened over 30 adjacent points using the adjacent averaging smoothing function in Origin $($ Pro 7.5 and plots were then area-normalized. Peaks were assigned according to the monoclinic unit cell described by Sugiyama et al. (1991). Peak positions and widths were measured from plots by using the method described by Gjønnes and Norman (1958). We did not use curve fitting software because of the complexity of the diffractograms, with peak positions and widths expected to be related to crystallite dimensions as well as crystalline forms of cellulose, as discussed below. Instead, we confined precise measurements to samples that had not been in contact with LiCl/DMAc.

The Scherrer equation was used to calculate the crystal thickness by using the half-width at half-height of the peak assigned to (200) planes:

$$
D=K \lambda /(B \cos \theta)
$$

where $D$ is the crystal thickness, $\lambda$ the radiation wavelength, $\theta$ the diffraction angle and $B$ the full width of the diffraction peak measured at half maximum height prior to smoothing. The correction factor, $K$, was set to 0.9 (Murdock 1930). A crystallinity index $C r I$ was used as defined by Segal et al. (1959):

$$
C r I=100(I-I) / I
$$

Here $I$ is the height of the peak assigned to (200) planes, typically located in the range $2 \theta=21^{\circ}$ to $22^{\circ}$, and $I^{\prime}$ is the height measured at $2 \theta=18^{\circ}$, which is where the maximum appears in a diffractogram of amorphous cellulose.

Solid state ${ }^{13}$ C nuclear magnetic resonance (NMR) 
Each composite was crushed to particle dimensions of $\sim 0.5 \mathrm{~mm}$, combined with a similar or larger weight of water, and packed into a zirconium oxide rotor. Excess water was expelled during packing to prepare samples with a typical solids content of $55 \%$ by dry weight. The rotor was sealed with a Kel-F® cap.

Solid state CP-MAS ${ }^{13} \mathrm{C}$ NMR spectra were obtained on a Bruker Avance DRX200 FTNMR spectrometer at a frequency of $50.3 \mathrm{MHz}$ and at a magic-angle spinning frequency of 5 $\mathrm{kHz}$. Each $90^{\circ}$ proton preparation pulse of $5 \mu$ s was followed by a delay $\tau$, a contact time of 1 $\mathrm{ms}$, acquisition time of $20 \mathrm{~ms}$, and a recycle delay of $1 \mathrm{~s}$. Two spectra were acquired for each sample and labelled $\mathbf{S}(\tau=1 \mu \mathrm{s})$ and $\mathbf{S}^{\prime}(\tau=15 \mu \mathrm{s})$. Bold type is used for these symbols since they represent vectors, i.e., lists of the signal heights measured across a range of chemical shifts. Transients from a minimum of 10,000 pulses were averaged in both cases.

Signals from crystalline cellulose were partly suppressed in $\mathbf{S}^{\prime}$, through relatively rapid $T_{2}(\mathrm{H})$ decay during the delay $\tau$. The discrimination was enhanced by proton spin relaxation editing (PSRE). This method is more commonly used to process spectra modified by rotatingframe relaxation (Newman 1999) but has been used to process spectra modified by $T_{2}(\mathrm{H})$ (Newman et al. 1996). PSRE involves computing linear combinations:

$$
\begin{aligned}
& \mathbf{A}=k \mathbf{S}+k^{\prime} \mathbf{S}^{\prime} \\
& \mathbf{B}=(1-k) \mathbf{S}-k^{\prime} \mathbf{S}^{\prime}
\end{aligned}
$$

The values of $k$ and $k^{\prime}$ are adjusted until signals assigned to poorly-ordered matter are excluded from $\mathbf{A}$ and signals well-ordered matter are excluded from $\mathbf{B}$. In this case, signals at $80 \mathrm{ppm}$ and 89 ppm were assigned to C-4 in poorly-ordered and crystallite-interior cellulose, respectively (Newman 1999). Details concerning the adjustment of $k$ and $k^{\prime}$ can be found elsewhere (Newman and Hemmingson 1995). The fraction $F$ of crystalline cellulose in each composite was estimated by dividing the area of $\mathbf{A}$ by area of $\mathbf{S}$. 
The subspectra labeled A showed two partly-resolved C-4 signals, assigned to crystalliteinterior and crystallite-surface glucosyl residues, at $89 \mathrm{ppm}$ and $84 \mathrm{ppm}$ respectively. Signal areas were delimited by the baseline and a vertical line drawn at $86.4 \mathrm{ppm}$. Relative areas were used to estimate the percentage $X$ of cellulose chains contained in crystallite interiors (Newman 1999). Assuming a simplified model of a square cellulose crystallite with cross-sectional dimensions $L \times L$ and only a monolayer of cellulose chains exposed to the surface, an estimate of the apparent average crystallite size can be given by the expression (Newman 1999):

$$
L=1.14 /\left(1-X^{1 / 2}\right)
$$

\section{Results and Discussion}

\section{WAXS diffractograms}

Activation showed only a minor effect on the WAXS diffractogram (Fig. 1). The peak assigned to (200) planes appeared at $2 \theta=22.6^{\circ}$ and $22.8^{\circ}$ in as-received MCC and activated MCC, respectively, as in published WAXS diffractograms for cellulose I (Isogai 1989; Ishii et al. 2003). The full widths $B$ at half maximum height were $1.75^{\circ}$ and $1.68^{\circ}$, giving crystal thicknesses of 4.5 and $4.9 \mathrm{~nm}$, respectively, according to Eq. (1).

Peaks at $2 \theta=15.1^{\circ}, 16.8^{\circ}$ and $34.8^{\circ}$ in the diffractogram for activated cellulose were also consistent with peaks in published WAXS diffractograms for cellulose I (Isogai 1989; Ishii et al. 2003). The crystallinity index $C r I$ calculated from Eq. (2) decreased from $87 \%$ for MCC to $80 \%$ after activation (Table 1).

The WAXS diffractograms for all-cellulose composites showed a small shoulder at $2 \theta=$ $20.8^{\circ}$ that progressively developed into a distinct diffraction peak with decreasing cellulose concentration in the solvent (Figs. 2, 3). The peak was more distinct in composites prepared with 
a dissolution time of 8 h (Fig. 3), relative to $1 \mathrm{~h}$ (Fig. 2). Plots for other dissolution times indicated that equilibrium was reached after approximately $4 \mathrm{~h}$, with little further change to $48 \mathrm{~h}$. Gindl and Keckes (2005) observed this peak in WAXS diffractograms of all-cellulose composites, and assigned it to regenerated cellulose. They observed a similar peak in a WAXS diffractogram of cellulose produced by dissolving cellulose II in LiCl/DMAc and regenerating it.

The peak at $2 \theta=20.8^{\circ}$ was $5.0^{\circ}$ wide at half maximum height, and this width was too small for the peak to be assigned to amorphous cellulose. Ball-milled cellulose is commonly used as a reference standard for amorphous cellulose. The peak position has been reported as $2 \theta$ $=18^{\circ}$ (Segal et al. 1959; Mann 1962) or $2 \theta=20^{\circ}$ (Schroeder et al. 1986), but it is generally agreed that the width is approximately $10^{\circ}$. The width of $5.0^{\circ}$, observed in Fig. 3, corresponds to a crystallite thickness of $D=1.6 \mathrm{~nm}$ according to Eq. (1). For (200) planes separated by $0.4 \mathrm{~nm}$ (Sugiyama et al. 1991) that corresponds to crystallites containing just 4 planes.

A commonly-used crystallinity index $C r I$, expressed in Eq. (2), exploits the fact that the maximum for amorphous cellulose falls between peaks in the diffractogram for cellulose I. The diffractograms in Figs. 2 and 3 showed increasing height at $2 \theta=18^{\circ}$, for increasing degrees of transformation, but the value of $C r I$ never dropped below 39\% (Table 1).

Gjønnes and Norman (1958) and Ioelovich and Larina (1999) reported lattice expansion in thin crystallites of cellulose I, so that an increase in peak width was associated with a displacement to low values of 20. A curve published by Gjønnes and Norman (1958) indicated that an increase in peak width to $7^{\circ}$ was sufficient to displace the peak to $2 \theta=21^{\circ}$. The peak at $2 \theta=20.8^{\circ}$ in Figs. 2 and 3 is therefore consistent with cellulose I crystallites split to fine dimensions.

When regenerated cellulose crystallizes to the cellulose II allomorph it shows WAXS peaks at $2 \theta=12.1^{\circ}, 19.8^{\circ}$ and $22.0^{\circ}$ (Isogai et al. 1989). Changes in lattice dimensions influence the positions of WAXS peaks for cellulose II, but the pattern of displacements is different from 
that for cellulose I. Gjønnes and Norman (1960) showed that the peak at $2 \theta=19.8^{\circ}$ is displaced to higher values, and the peak at $2 \theta=22.0^{\circ}$ to lower values, as the peaks broaden. Extrapolation from their data suggested that the two peaks might form a single peak, with a width of approximately $7^{\circ}$, at a value of $2 \theta$ somewhere between $20^{\circ}$ and $21^{\circ}$. Yamashiki et al. (1992) confirmed movement towards an intermediate value of $2 \theta$ by published WAXS diffractograms for cellulose II as viscose and cuprammonium rayons, showing a broad peak at $2 \theta=20.0^{\circ}$ with a shoulder at $2 \theta=21.6^{\circ}$. The peak at $2 \theta=20.8^{\circ}$ in Fig. 3 is therefore indistinguishable from the pattern predicted for very narrow crystallites of cellulose II.

Cellulose III, when prepared from cellulose I, shows a strong WAXS peak $2 \theta=20.7^{\circ}$ and a weaker peak $2 \theta=11.7^{\circ}$ (Isogai et al. 1989). The former peak matched the broad peak in WAXS diffractograms of the most severely treated specimens (Figs. 2 and 3), but the latter was not observed.

The peak assigned to (200) planes of cellulose I remained visible as a shoulder at $2 \theta=$ $22.3^{\circ}$ in WAXS diffractograms of specimens with the greatest degrees of transformation, i.e., the lower two traces in Figs. 2 and 3. The shoulder was too weak for measurement of the peak width, but the curve published by Gjønnes and Norman (1958) indicated that displacement to $2 \theta=$ $22.3^{\circ}$ corresponded to a peak width of $3^{\circ}$, for which Eq. (1) indicated a crystallite thickness of approximately $3 \mathrm{~nm}$. The diffractogram of MCC (Fig. 1) showed a peak assigned to (004) planes. This peak was weak or absent in diffractograms of all-cellulose composites prepared with the greatest degrees of transformation, e.g., the lowest diffractogram in Fig. 3. The disappearance of this peak suggests longitudinal disorder, consistent with a paracrystalline matrix.

Solid-state ${ }^{13}$ C NMR 
The ${ }^{13} \mathrm{C}$ NMR spectrum of activated MCC (Fig. 4) resembled a published spectrum of Avicel MCC (Newman and Hemmingson 1995), confirming WAXS indications of little change in molecular packing associated with activation. Minor changes were revealed by PSRE (Fig. 4). In the published PSRE results (Newman and Hemmingson 1995) subspectrum A accounted for $84 \%$ of the area of the total spectrum $\mathbf{S}$. This proportion decreased to $73 \%$ after activation (Fig. 4), indicating transformation of some of the cellulose I to a less ordered form of cellulose. A published ${ }^{13} \mathrm{C}$ NMR study of Avicel MCC indicated a crystallite width of $L=5.9 \mathrm{~nm}$ (Newman 1999). Peak areas in subspectrum A of Fig. 4, interpreted according to the same procedure, indicated a crystallite width of $L=6.3 \mathrm{~nm}$ for activated MCC (Table 1).

Fig. 5 shows ${ }^{13} \mathrm{C}$ NMR spectra of the composites regenerated after a dissolution time of 8 h. Peaks are assigned to cellulose I, as in Fig. 4. Cellulose II would have contributed a peak at 108 ppm, assigned to C-1 in crystallite-interior chains (Hemmingson and Newman 1995; Newman and Hemmingson 1995). No such peak was detected in Fig. 5, so there was no evidence for regeneration to cellulose II in crystallites of sufficient size for chains to be enclosed.

A peak at 89 ppm was assigned to C-4 peak of crystallite-interior chains of cellulose I. This peak was observed in all of the spectra in Fig. 5, but decreased with decreasing values of $c$. PSRE was used to split the NMR spectra into subspectra labeled A (Fig. 6), assigned to crystalline cellulose, and subspectra labeled B (Fig. 7), assigned to cellulose that was less well ordered.

The fraction $F$ of cellulose associated with subspectrum A dropped steadily from 0.84 for MCC to $F=0.24$ for the composite treated for $8 \mathrm{~h}$ at $c=10 \%$, then rose to $F=0.37$ for $c=5 \%$ (Table 1). The last of these values might have been distorted by the difficulty in separating subspectra $\mathbf{A}$ and $\mathbf{B}$.

Relative peak areas within subspectrum A were used to calculate $X$, i.e., the crystalliteinterior cellulose expressed as \% of crystalline cellulose contributing to subspectrum $\mathbf{A}$. The 
values (Table 1) confirmed the visual impression (Figs. 5, 6) of a steady decline in $X$ as the value of $c$ was decreased. The values of $X$ were used to calculate crystallite widths $L$, according to Eq. (5). Values (Table 1) indicated a decrease to $L=2.3 \mathrm{~nm}$ for the most severe treatment.

The chemical shift for C-4 is particularly sensitive to the conformation of a cellulose chain (Horii et al. 1987). Chemical shifts in the range 79 to $81 \mathrm{ppm}$ are characteristic of the random-coil conformation of cellulose dissolved in trifluoroacetic acid (Bock et al. 1991) or regenerated as amorphous cellulose (Hirai et al. 1990; Newman and Hemmingson 1995). Chemical shifts in the range 84 to $90 \mathrm{ppm}$ are characteristic of the linear conformations of chains in crystalline cellulose (Horii et al. 1987). El-Kafrawy (1982) dissolved cellulose in LiCl/DMAc and observed a C-4 peak at 79 ppm, confirming a true solution of random-coil cellulose. All of the traces in Fig. 7 showed a dip at 80 ppm, labeled C-4a, but the fact that the dip did not extend to the baseline suggested a contribution from amorphous cellulose. Most of the C-4 signal area was found in a peak at $84 \mathrm{ppm}$, i.e., the same chemical shift as reported for C-4 in cellulose chains in linear molecular conformations exposed on the surfaces of cellulose I, with hydroxymethyl groups in the gauche-gauche conformation (Newman and Davidson 2004). The C-6 signal area was found in a peak at $62 \mathrm{ppm}$, also consistent with chains exposed on surfaces of cellulose I (Newman and Davidson 2004). It is possible to construct models for crystallites of cellulose I in which all chains are exposed on surfaces, but the widths must be no more than 2 $\mathrm{nm}$. Such crystallites might be described as 'paracrystalline', so we have used the label C-4p in Fig. 7.

The combination of C-4 and C-6 peaks at 84 and 62 ppm, respectively, has also been reported for the NMR spectrum of cellulose IV (Isogai et al. 1989). This is consistent with a suggestion that cellulose IV is simply a poorly-crystalline form of cellulose I (Tsuda and Mukoyama 1957; Wada et al. 2004). Cellulose IV has been identified as a product of the viscose process for regenerating cellulose (Tsuda and Mukoyama 1957). 
Chemical shifts for crystallite-surface chains in cellulose II have been reported as 88.0 and $86.5 \mathrm{ppm}(\mathrm{C}-4 \mathrm{~s})$ and 63.2 and $62.9 \mathrm{ppm}(\mathrm{C}-6 \mathrm{~s})$ (Newman and Davidson 2004). Those chemical shifts differ from the values observed in Fig. 7. Hong (1998) reported evidence for cellulose III in cellulose fibre regenerated from $\mathrm{LiCl} / \mathrm{DMAc}$. The chemical shifts for crystalliteinterior cellulose III are similar to those for cellulose II (Isogai et al. 1989), but crystallitesurface signals have not been reported.

The relevant proton spin relaxation time constants provide clues to the nature of the matrix. The experiments described in this paper were based on differences in $T_{2}(\mathrm{H})$ between crystallites and the matrix. Subspectra were separated from spectra of the primary walls of Arabidopsis thaliana by Newman et al. (1996), and the values of $k$ and $k$ ' in Eq. (3) indicated $T_{2}(\mathrm{H})=8.5 \mu \mathrm{s}$ and $19 \mu \mathrm{s}$ for crystalline cellulose and amorphous matrix polysaccharides, respectively. Using the same expressions for $k$ and $k^{\prime}$ in the present work indicated $T_{2}(\mathrm{H})=8.6$ $\mu \mathrm{s}$ and $11 \mu \mathrm{s}$ for crystallites and matrix, respectively. The value of $T_{2}(\mathrm{H})$ for the cellulosic matrix was not greatly increased over the value for the crystallites, suggesting paracrystallinity rather than amorphicity.

The subspectra stacked in Fig. 7 could not be used to determine the relative proportions of paracrystalline and amorphous cellulose, since the C-4 peaks were not resolved. Overlap between the C-4 and C-2,3,5 bands might even account for much of the signal strength in the dip at $80 \mathrm{ppm}$.

Kondo et al. (2001) introduced the concept of 'nematic ordered cellulose' to cover intermediate states of molecular ordering such as those described in this work, i.e., states that display some of the features of each of the crystalline allomorphs of cellulose, yet no perfect match to any one of those allomorphs. 
The WAXS index CrI showed strong correlations with both of the NMR indices tabulated in Table 1. Linear least-squares fits gave correlation coefficients $R^{2}=0.92$ and 0.94 for $C r I$ against $F$ and $X$ respectively. The correlation coefficient rose to $R^{2}=0.99$ for $C r I$ against the product $F X$, i.e., crystallite-interior cellulose expressed as $\%$ of total cellulose.

The crystallite dimensions $D$ and $L$ showed similar trends, i.e., decreasing cross-sectional dimensions as a result of partial dissolution. A perfect match was not expected for these parameters, since they represent cross-sectional measurements in orthogonal directions: $D$ perpendicular to the (200) planes, $L$ across those planes (Newman 1999).

\section{Transformation mechanisms}

When considered together, the WAXS and NMR results suggest the following mechanism.

Exposure to $\mathrm{LiCl} / \mathrm{DMAc}$ peels layers of cellulose from crystallites. The residual core of the crystallite becomes thinner as successive layers are removed. The peeled layers might retain some of the molecular ordering of the cellulose I structure from which they were removed, but are too thin to contain crystallite-interior chains. When the $\mathrm{LiCl}$ and DMAc are washed away, the peeled layers of cellulose are regenerated into a paracrystalline matrix. The paracrystalline structures are sufficiently disordered to show $T_{2}(\mathrm{H})$ values slightly longer than those characteristic of crystalline cellulose. On the other hand, they are sufficiently distinct from amorphous cellulose to show a WAXS peak just half as broad. They are also sufficiently distinct to show a 4 ppm displacement of the C-4 ${ }^{13} \mathrm{C}$ NMR peak, from 80 ppm for amorphous cellulose to $84 \mathrm{ppm}$ for the matrix of the composites. 
The partly-ordered nature of the matrix helps account for the superior mechanical properties observed for all-cellulose composites.

Using relatively high concentrations of cellulose in $\mathrm{LiCl} / \mathrm{DMAc}$ has several advantages. Above all else, it minimizes the shrinkage undergone by the material during the precipitation and drying stage. This minimizes many manufacturing constraints like large mould opening, shape loss or amount of residual water in the material before drying. There are also financial, environmental and health interests in minimizing the amount of solvent used for a given amount of polymer. Conio et al. (1984) suggested that a concentration $c<15 \%$ was necessary for partial dissolution in $8 \% \mathrm{LiCl} / \mathrm{DMAc}$, and a concentration $\mathrm{c}<11 \%$ was necessary for complete dissolution. Our results show that partial dissolution could be observed at $c=20 \%$. More work is required to test whether the degree of transformation was sufficient to provide satisfactory mechanical properties. Transformation was nearly complete for $\mathrm{c}=10 \%$, but we detected a trace of residual crystalline cellulose.

\section{Conclusions}

Partial dissolution and regeneration of cellulose, using LiCl/DMAc, yields all-cellulose composites with a matrix comprising a mixture of paracrystalline and amorphous cellulose. Both WAXS and NMR results point to distinct differences from a fully amorphous matrix. More work is needed to test the consequences of paracrystallinity on the mechanical properties of allcellulose composites.

\section{Acknowledgements}


The authors would like to thank the Biopolymer Network Limited (New Zealand) for financial assistance and technical support provided to this project. One of the authors (MPS) would like to thank the Brian Mason Scientific and Technical Trust for financial assistance. The authors thank

Mr. S. Hill (Scion Limited, Rotorua, New Zealand) for assistance with solid-state NMR and Mr. S. Brown for acquisition of the WAXS patterns.

\section{References}

Bledzki AK, Gassan J (1999) Composites reinforced with cellulose based fibres. Progress in Polymer Science 24:221-274

Bock B, Bock S, Fengel D (1991) NMR parameters of cellulose in TFA solution. Holzforschung $45: 321-324$

Conio G, Corazza P, Bianci E, Taldi A, Ciferri A (1984) Phase-equilibria of cellulose in N,Ndimethylacetamide/LiCl solutions. Journal of Polymer Science Part C - Polymer Letters $22: 273-277$

Dupont A-L (2003) Cellulose in lithium chloride/N,N-dimethylacetamide, optimisation of a dissolution method using paper substrates and stability of the solutions. Polymer $44: 4117-4126$

El-Kafrawy A (1982) Investigation of the cellulose/LiCl/dimethylacetamide and cellulose/LiCl/N-methyl-2-pyrrolidone solutions by ${ }^{13} \mathrm{C}$ NMR spectroscopy. Journal of Applied Polymer Science 27:2435-2443

Gindl W, Keckes J (2004) Tensile properties of cellulose acetate butyrate composites reinforced with bacterial cellulose. Composites Cellulose and Technology 64:2407-2413

Gindl W, Keckes J (2005) All-cellulose nanocomposite. Polymer 46:10221-10225 
Gindl W, Martinschitz KJ, Boesecke P, Keckes J (2006a) Structural changes during tensile testing of an all-cellulose composite by in situ synchrotron X-ray diffraction. Composites Science and Technology 66:2639-2647

Gindl W, Schöberl T, Keckes J (2006b) Structure and properties of a pulp fibre-reinforced composite with regenerated cellulose matrix. Applied Physics A - Materials Science \& Processing 83:19-22

Gjønnes J, Norman N (1958) The use of half width and position of the lines in the X-ray diffractograms of native cellulose to characterize the structural properties of the samples. Acta Chemica Scandinavica 12:2028-2033

Gjønnes J, Norman N (1960) X-ray investigations on cellulose II and mixtures of cellulose I and II. 2. Lateral order in cellulose II. Acta Chemica Scandinavica 14:689-691

Glasser WG, Taib R, Jain RK, Kander R (1999) Fiber-reinforced cellulosic thermoplastic composites. Journal of Applied Polymer Science 73:1329-1340

Hemmingson JA, Newman RH (1995) Changes in molecular ordering associated with alkali treatment and vacuum drying of cellulose. Cellulose 2:71-82

Hirai A, Horii F, Kitamaru R (1990) Carbon-13 spin-lattice relaxation behaviour of the crystalline and noncrystalline components of native and regenerated celluloses. Cellulose Chemistry and Technology 24:703-711

Hong Y-K, Chung K-H, Lee W-S (1998) Structure of regenerated cellulose fibers from DMAc/LiCl solution. Textile Research Journal 68:65-69

Horii F, Hirai A, Kitamaru R (1987) Cross-polarization-magic angle spinning carbon-13 NMR approach to the structural analysis of cellulose. In: Atalla RH (ed) The Structures of Cellulose: Characterization of the Solid States. American Chemical Society, Washington DC, p1 19 
Ioelovich M, Larina E (1999) Parameters of crystalline structure and their influence on the reactivity of cellulose I. Cellulose Chemistry and Technology 33:3-12

Ishii D, Tatsumi D, Matsumoto T (2003) Effect of solvent exchange on the solid structure and dissolution behavior of cellulose. Biomacromolecules 4:1238-1243

Isogai A, Usuda M, Kato T, Uryu T, Atalla RH (1989) Solid-state CP/MAS ${ }^{13}$ C NMR study of cellulose polymorphs. Macromolecules 22:3168-3172

Kondo T, Togawa E, Brown Jr RM (2001) "Nematic ordered cellulose”: a concept of glucan chain association. Biomacromolecules 2:1324-1330

Kroon-Batenburg LMJ, Kroon J, Northolt MG (1990) Theoretical studies on $\beta(1 \rightarrow 4)$ glucose oligomers as models for native and regenerated cellulose fibres. Das Papier 44:640-647

Lu JZ, Wu QL (2000) Chemical coupling in wood fiber and polymer composites: A review of coupling agents and treatments. Wood and Fiber Science 32:88-104

Mann J (1962) Modern methods of determining crystallinity in cellulose. Pure and Applied Chemistry 5:91-105

McCormick CL, Callais PA, Brewer Jr HH (1985) Solution studies of cellulose in lithium chloride and N,N-dimethylacetamide. Macromolecules 18:2394-2401

Murdock CC (1930) The form of the X-ray diffraction bands for regular crystals of colloidal size. Phys Rev 35:8-23

Newman RH (1999) Estimation of the lateral dimensions of cellulose crystallites using 13C NMR signal strengths. Solid State Nuclear Magnetic Resonance 15:21-29

Newman RH, Davies LM, Harris PJ (1996) Solid-state ${ }^{13} \mathrm{C}$ nuclear magnetic resonance characterization of cellulose in the cell walls of Arabidopsis thaliana leaves. Plant Physiol 111:475-485

Newman RH, Davidson TC (2004) Molecular conformations at the cellulose-water interface. Cellulose 11:23-32 
Newman RH, Hemmingson JA (1995) Carbon-13 NMR distinction between categories of molecular order and disorder in cellulose. Cellulose 2:95-110

Nishino T, Matsuda I, Hirao K (2004) All-cellulose composite. Macromolecules 37:7683-7687

Nishino T, Takano K, Nakamae K (1995) Elastic modulus of the crystalline regions of cellulose polymorphs. Journal of Polymer Science: Part B: Polymer Physics 33:1647-1651

Schroeder LR, Gentile VM, Atalla RH (1986) Nondegradative preparation of amorphous cellulose. Journal of Wood Chemistry and Technology 6:1-14

Segal L, Creely JJ, Martin AE, Conrad CM (1959) An empirical method for estimating the degree of crystallinity of native cellulose using the X-ray diffractometer. Textile Research Journal 29:786-794

Striegel AM (2002) Advances in the understanding of the dissolution mechanism of cellulose in DMAc/LiCl. J. Chilean Chem. Soc 48:73-77

Sugiyama J, Vuong R, Chanzy H (1991) Electron diffraction study on the two crystalline phases occurring in native cellulose from an algal cell wall. Macromolecules 24:4168-4175

Tsuda Y, Mukoyama S (1957) The formation of cellulose IV in the viscose spinning. Bulletin of the Chemical Society of Japan 30:718-720

Wada M, Heux L, Sugiyama J (2004) Polymorphism of cellulose I family: reinvestigation of cellulose IV. Biomacromolecules 5:1385-1391

Yano H, Sugiyama J, Nakagaito AN, Nogi M, Matsuura T, Hikita M, Handa K (2005) Optically transparent composites reinforced with networks of bacterial nanofibers. Advanced Materials 17:153-155 
Table 1. Data for starting materials and all-cellulose composites prepared by partial dissolution for $8 \mathrm{~h}$ at cellulose concentrations $c$ expressed as $\%$ of the total weight of cellulose, $\mathrm{LiCl}$ and DMAc.

\begin{tabular}{llllll}
\hline Sample & $C r I(\%)$ & $D(\mathrm{~nm})$ & $F$ & $X(\%)$ & $L(\mathrm{~nm})$ \\
\hline MCC & 87 & 4.5 & $(0.84)^{\mathrm{a}}$ & $(65)^{\mathrm{a}}$ & $(5.9)^{\mathrm{a}}$ \\
Activated & 80 & 4.8 & 0.73 & 67 & 6.3 \\
$c=20 \%$ & 71 & $-\mathrm{b}$ & 0.56 & 61 & 5.2 \\
$c=15 \%$ & 59 & $-\mathrm{b}$ & 0.52 & 49 & 3.8 \\
$c=10 \%$ & 39 & $-\mathrm{b}$ & 0.24 & 32 & 2.6 \\
$c=5 \%$ & 39 & $-\mathrm{b}$ & 0.37 & 24 & 2.3 \\
\hline
\end{tabular}

${ }^{a}$ literature values (Newman and Hemmingson 1995)

${ }^{\mathrm{b}}$ not done because of peak overlap 


\section{FIGURE CAPTIONS}

Figure 1 WAXS diffractograms of MCC before and after activation. Peaks assignments use the monoclinic cellulose I unit cell of Sugiyama et al. (1991).

Figure 2 WAXS diffractograms of all-cellulose composites prepared from activated cellulose by partial dissolution for $1 \mathrm{~h}$ with values of $c$ shown above each trace.

Figure 3 WAXS diffractograms of all-cellulose composites prepared from activated cellulose by partial dissolution for $8 \mathrm{~h}$ with values of $c$ shown above each trace.

Figure 4 Solid-state ${ }^{13} \mathrm{C}$ NMR spectra of activated cellulose. Experimental results are labeled $\mathbf{S}$ and $\mathbf{S}^{\prime}$. PSRE subspectra $\mathbf{A}$ and $\mathbf{B}$ are assigned to crystalline and less-ordered cellulose, respectively.

Figure 5 Solid-state ${ }^{13} \mathrm{C}$ NMR spectra of all-cellulose composites prepared from activated cellulose mixed with solvent at the weight \% values shown above each trace and left for $8 \mathrm{~h}$ of dissolution.

Figure 6 Subspectra A separated from solid-state ${ }^{13} \mathrm{C}$ NMR spectra of all-cellulose composites prepared from activated cellulose mixed with solvent at the weight $\%$ values shown above each trace and left for $8 \mathrm{~h}$ of dissolution. Labels $\mathrm{C}-4 \mathrm{i}$ and $\mathrm{C}-4 \mathrm{~s}$ indicate chemical shifts for chains in the interior and on surfaces, respectively, of cellulose I crystallites.

Figure 7 Subspectra $\mathbf{B}$ separated from solid-state ${ }^{13} \mathrm{C}$ NMR spectra of all-cellulose composites prepared from activated cellulose mixed with solvent at the weight $\%$ values shown above each trace and left for $8 \mathrm{~h}$ of dissolution. Labels $\mathrm{C}-4 \mathrm{a}$ and $\mathrm{C}-4 \mathrm{p}$ indicate chemical shifts for amorphous and paracrystalline cellulose, respectively. 


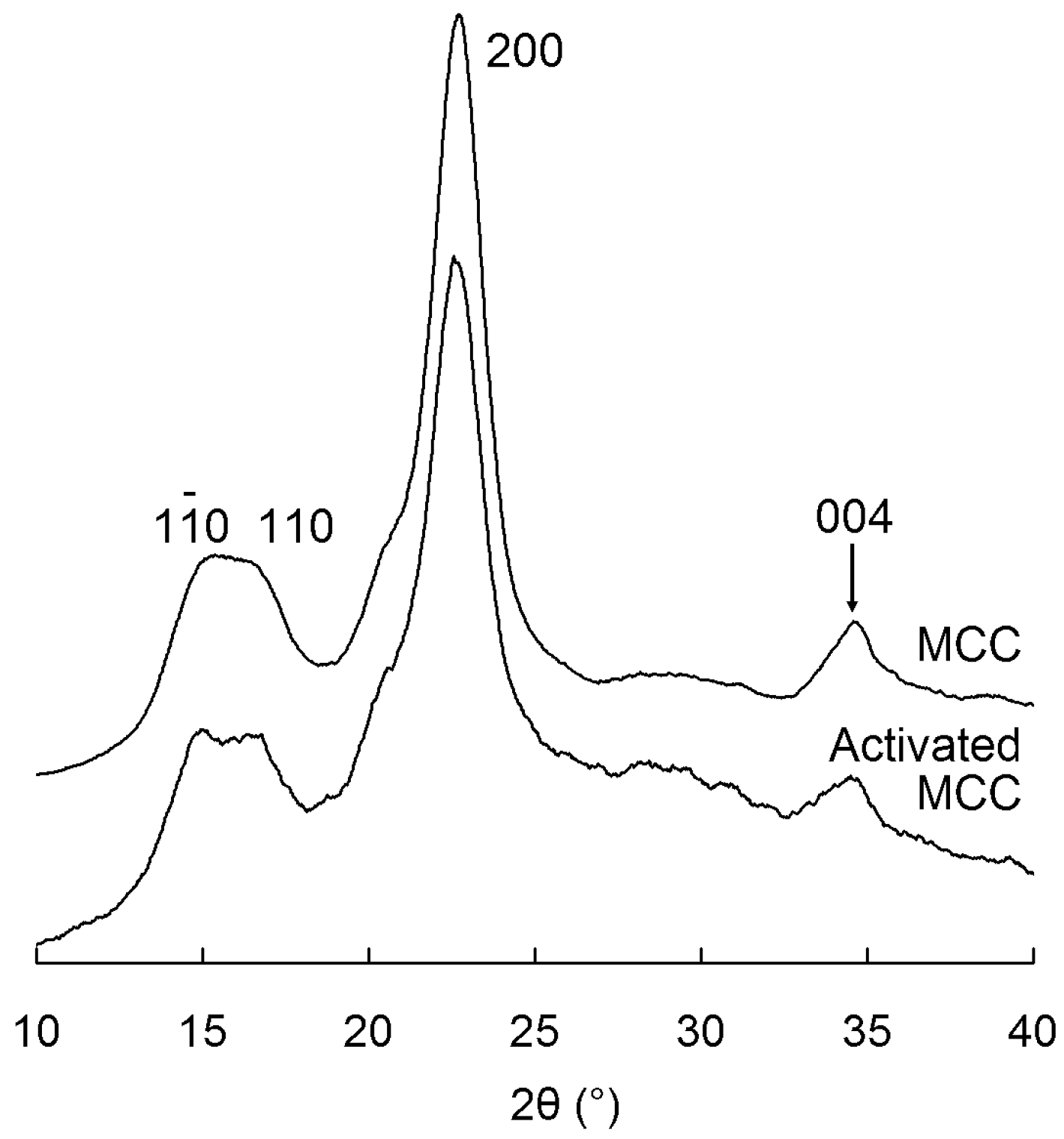

Fig. 1 


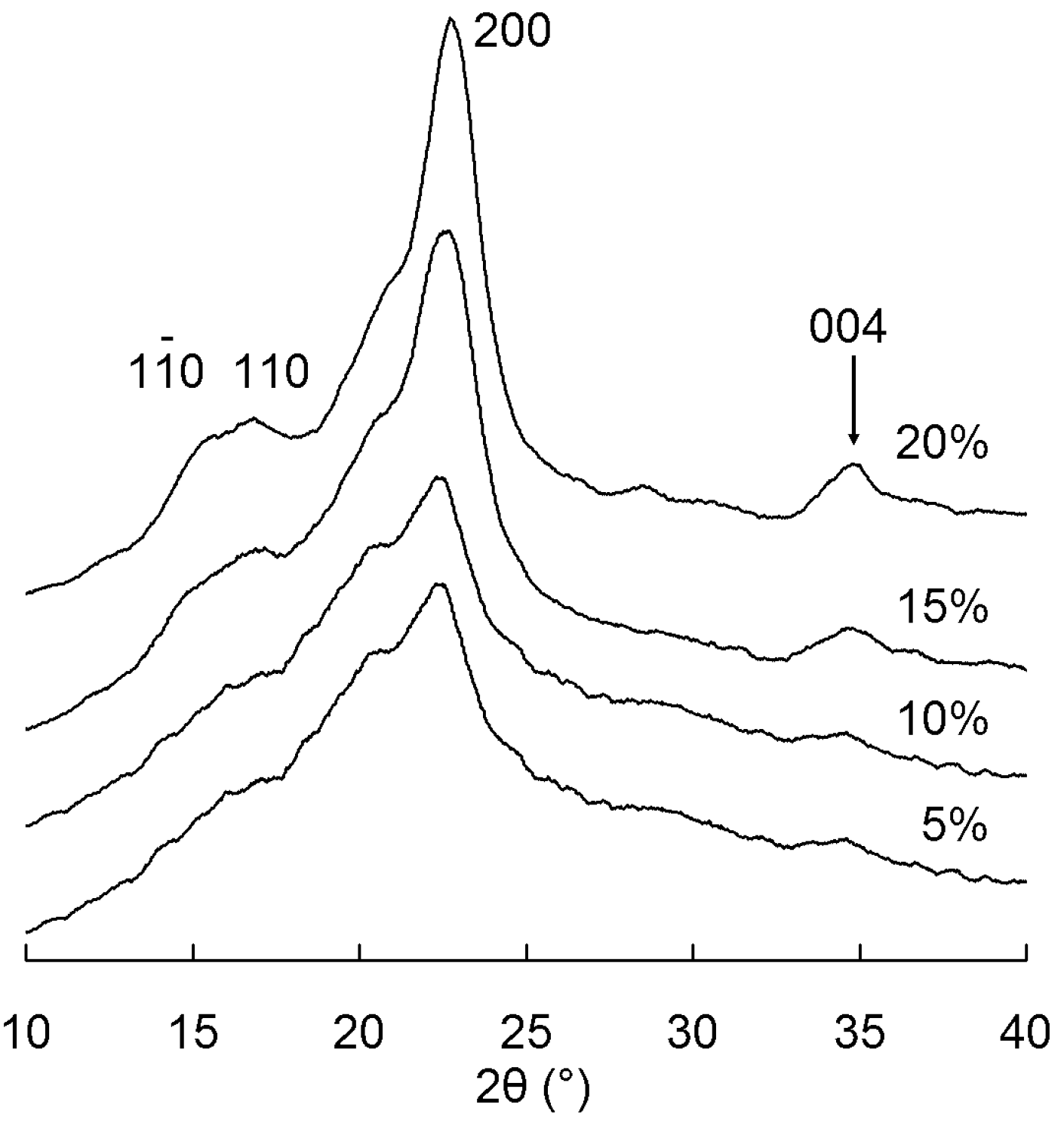

Fig. 2 


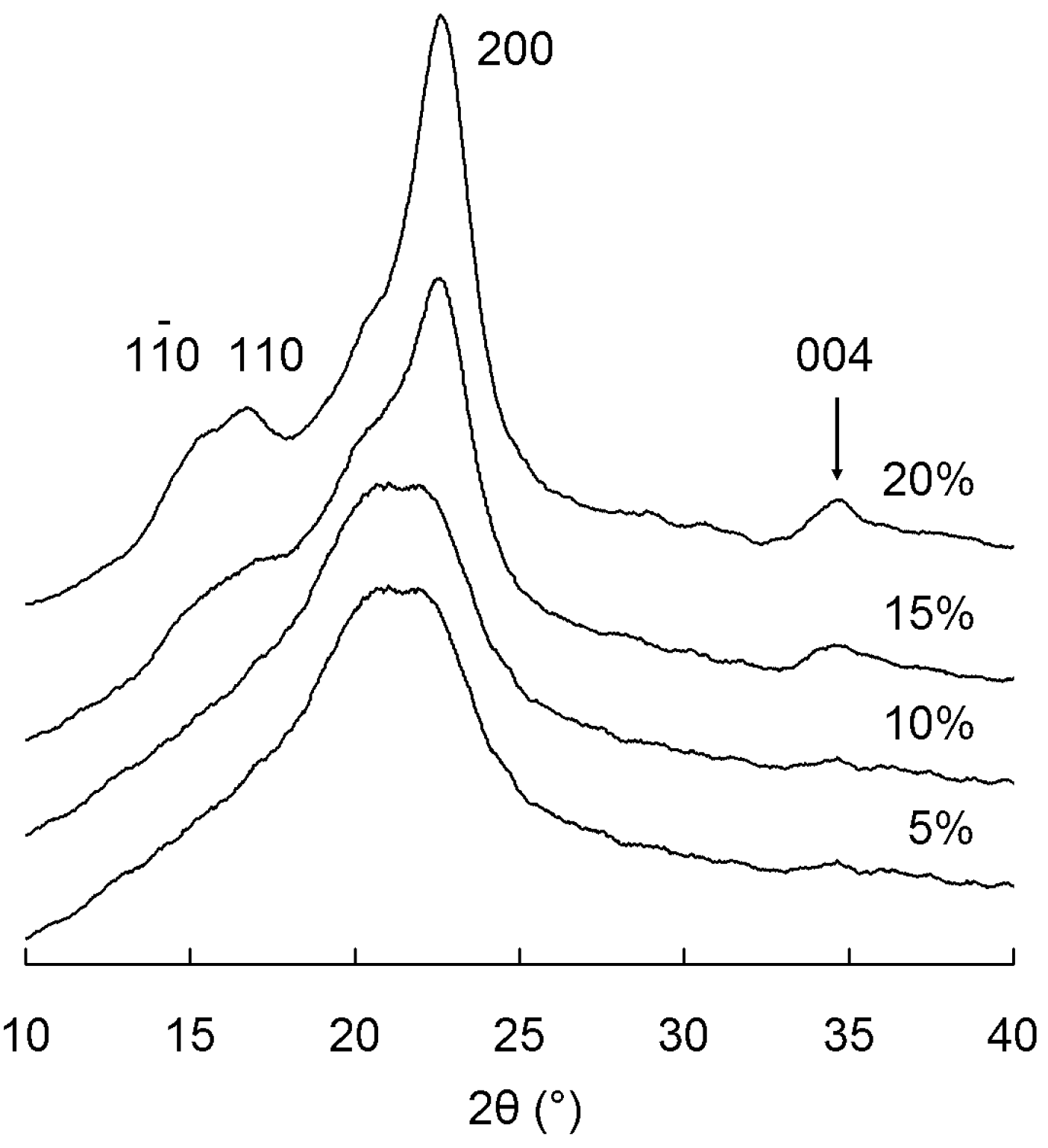

Fig. 3 


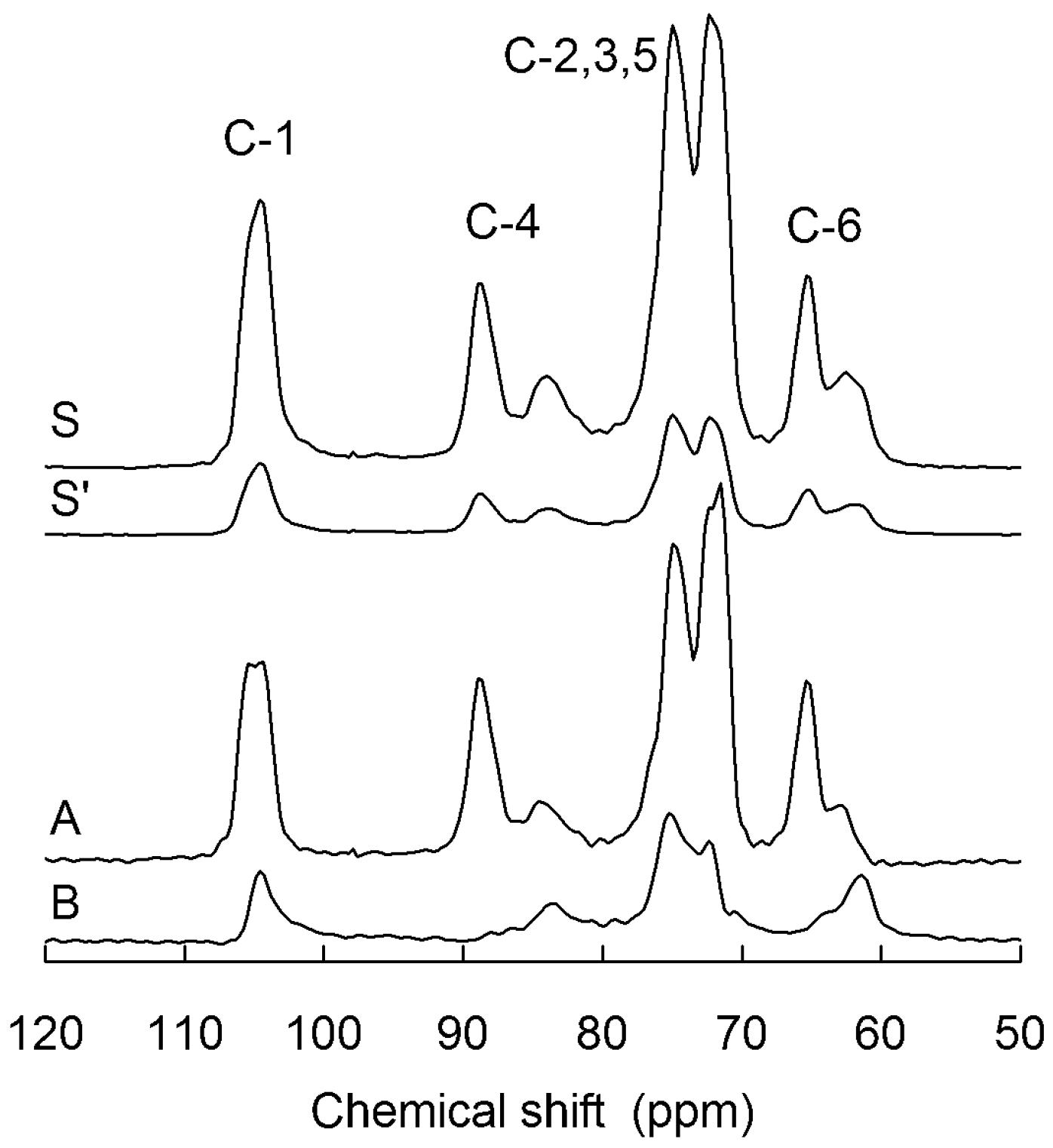

Fig. 4 


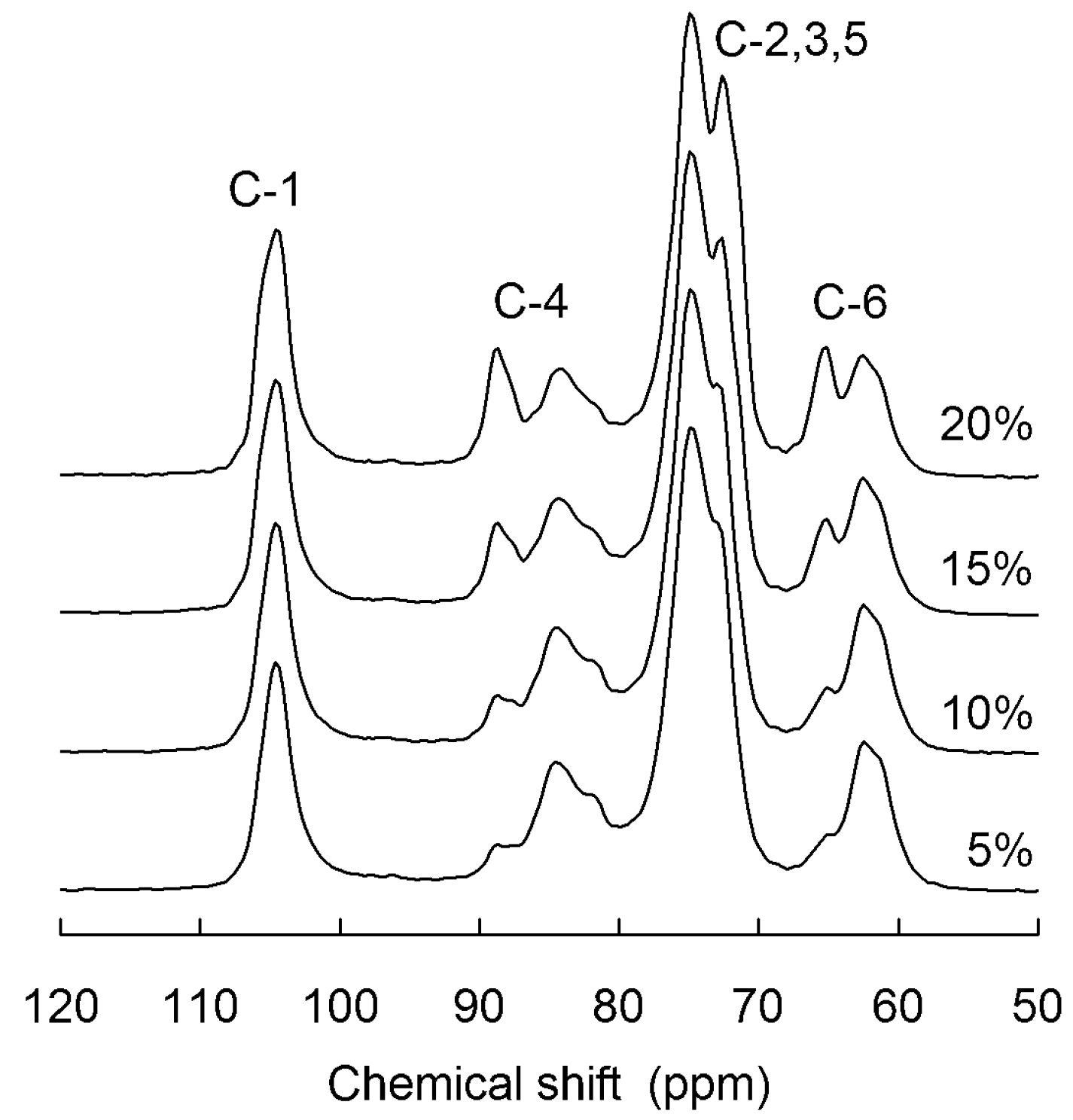

Fig. 5 


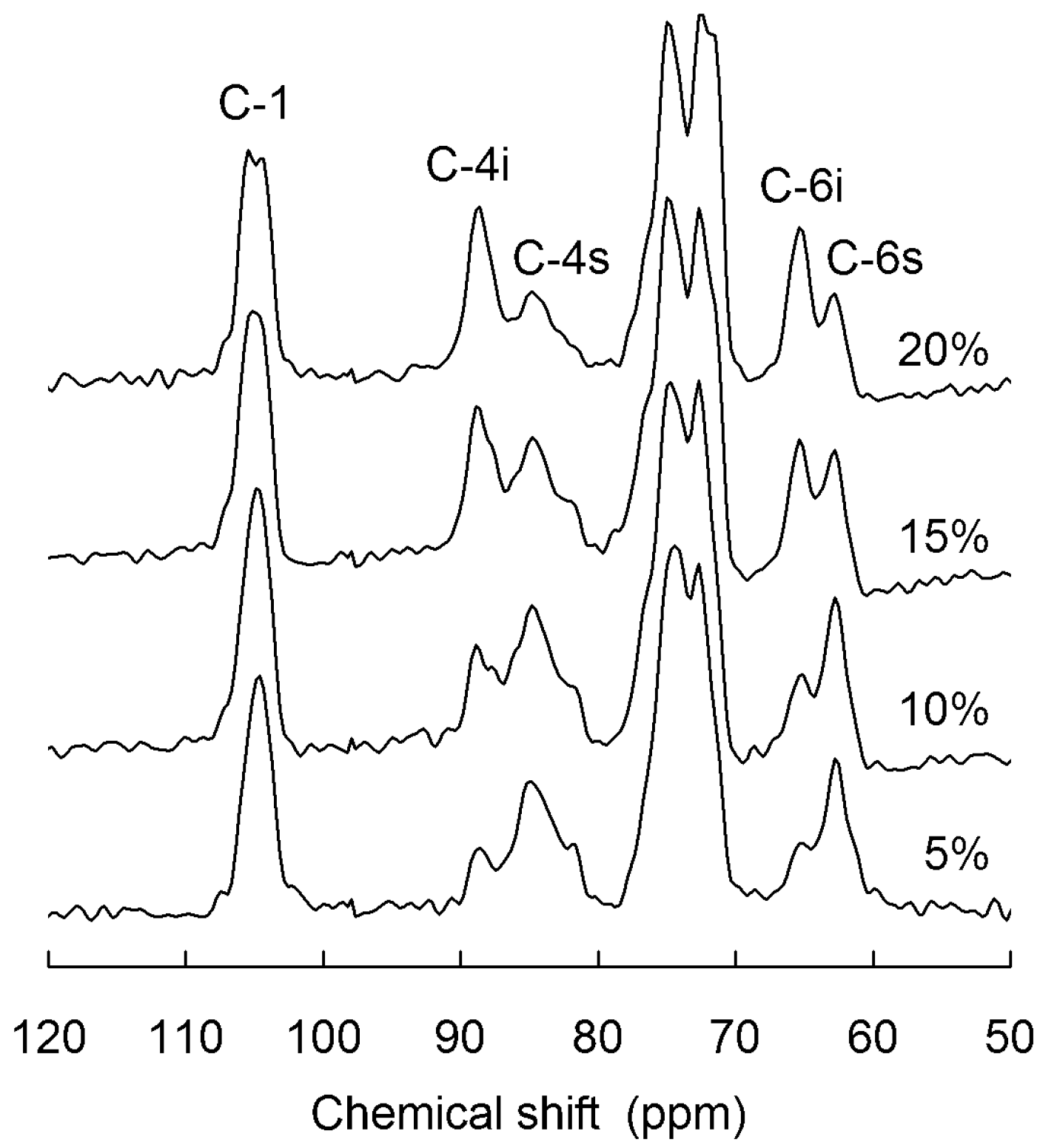

Fig. 6 


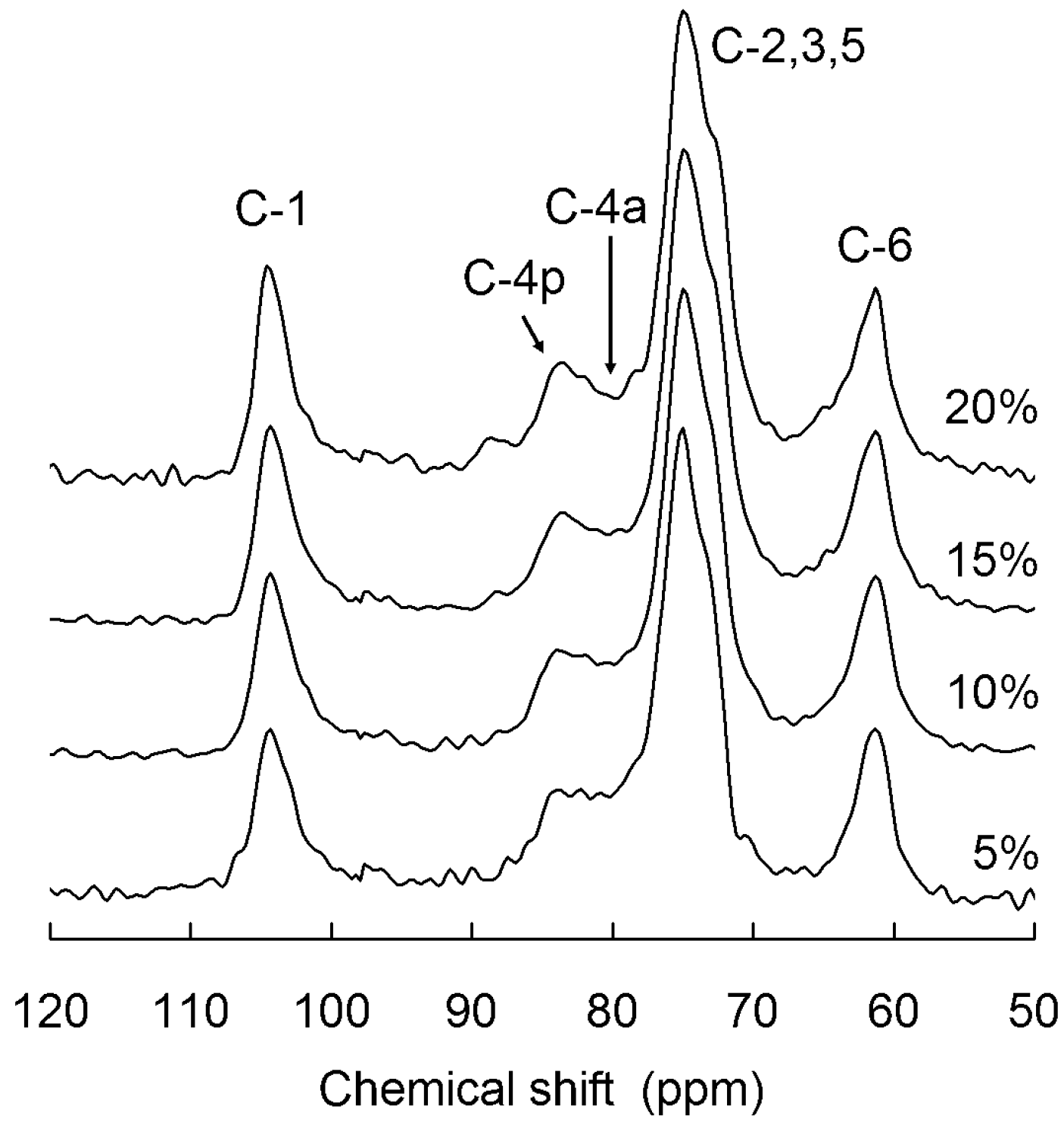

Fig. 7 